\title{
The Effects of PNF Pattern Training on the Walking Ability of Total Knee Replacement Patients
}

\author{
Jin Park \\ Department of Physical Therapy, Drim Sol Hospital \\ 507, Cheonjam-ro, Wansan-gu, Jeonju-si, Jeollabuk-do, 54877 \\ Republic of Korea \\ Received: January 9, 2021. Revised: June 15, 2021. Accepted: July 8, 2021. Published: July 14, 2021.
}

\begin{abstract}
The purpose of this study was to verify the effectiveness of proprioceptive neuromuscular facilitation pattern to improve walking ability of total knee replacement patients. In this study, 10 patients with total knee replacement were recruited from rehabilitation hospital. They were divided into two groups: a PNF group $(n=5)$ and a control group $(n=5)$. The PNF group received 30 minutes of continuous passive motion (CPM) and PNF training for 15 minutes five times a week for two weeks. The control group received 30 minutes of CPM and strengthening exercise for 15 minutes five times a week for two weeks. Spatiotemporal parameters were measured by Biodex gait trainer 2. After the training periods, the PNF group showed a significant improvement in walking speed and step length on the non-operated side, time on each foot on the operated side $(p<0.05)$. The results of this study showed that PNF pattern training was more effective at improving walking ability. Therefore, improve the walking ability of total knee replacement patients, PNF lower pattern should be considered.
\end{abstract}

Keywords-Gait, Proprioceptive neuromuscular facilitation, Strength, Total knee replacement

\section{INTRODUCTION}

$\Upsilon$ HE knee joint is an important joint that provides stability and mobility at the same time by distributing weight and absorbing stress from the ground. It is a site where degenerative arthritis is frequent due to weakening of leg muscle strength and changes in joint shape as aging progresses [1][2]. Degenerative knee arthritis is prevented and managed through medication, physical therapy, and exercise therapy, but total knee replacement (TKR) is performed if the condition is severe. TKR is helpful in controlling pain and performing functional movements, but walking ability decreases due to weakness in leg muscle strength [3][4].

Looking at the gait characteristics of patients with TKR, the reduction in weight-bearing ability and opposite step length due to weakening of the muscle strength of the operating leg, antalgic gait due to pain, walking speed and gait endurance decreased [5]. In order to improve the gait ability of patients with such TKR, the hip joint spreader is an important factor to consider [6]. The hip abductor muscle is involved in the transmission and stability of the force from the pelvis to the leg, and can be seen as a more important muscle than the knee extensor in patients with TKR [7].

In order to improve this problem, many previous studies have been conducted to strengthen the hip abductor muscle. In a study by Harikesavan et al. [6], it was reported that strengthening exercise for the hip abductor muscle was effective in improving physical function and improving walking speed in patients with TKR. In a study by Petterson et al. [8], it was reported that muscle strength exercise for the hip abductor muscle was effective in improving pelvic stability and walking ability in patients with TKR. Based on this, it can be seen that TKR patients need to strengthen the muscle strength of the hip abductor muscle.

The proprioceptive neuromuscular facilitation (PNF) lower extremity pattern can be applied to strengthen the weakened hip abductor muscle. PNF is an approach that integrates motor control and motor learning. It is an effective method to improve muscle strength, endurance, joint motion range through pattern movement consisting of diagonal motion [9]. Among the PNF patterns, strengthen the hip abductor muscle include hip flexion-abduction-internal rotation pattern and hip joint extension-abduction-external rotation pattern [10].

In the case of TKR patients, it is possible to consider strengthening the hip abductor muscle strength by applying the PNF pattern because the walking ability is affected by the weakness of the hip adductor muscle among leg muscle strength. However, it is necessary to verify the effect on the spatio-temporal gait variables as a result of the PNF pattern application's effect on walking ability is not directly verified. Therefore, in this study, we tried to verify the effect of PNF lower limb pattern application on the gait ability by strengthening the abductor muscle of the hip joint.

\section{METHODS}

\section{A. Subjects}

From June 2020 to October 2020, among patients admitted to a rehabilitation hospital located in J City, Korea, based on the Declaration of Helsinki, the study was conducted based on the subjects who understood the purpose of the study and agreed to participate. Of a total of 13 patients, 10 people 
participated in the study, excluding 3 patients whose gait parameters were difficult to measure due to pain. Participants in the study were patients who had TKR on one leg due to osteoarthritis, who were able to walk independently and who could follow the instructions of the investigator, and had a manual muscle strength test score of 3 or more. Patients with TKR due to external injury other than osteoarthritis were excluded. The general characteristics of the subjects are as shown in Table 1 , and there was no statistically significant difference $(\mathrm{p}>0.05)$.

Table 1. General characteristics of subjects

\begin{tabular}{|c|c|c|}
\hline Characteristics & $\begin{array}{l}\text { PNF group } \\
\quad(n=5)\end{array}$ & $\begin{array}{c}\text { Control group } \\
(\mathrm{n}=5)\end{array}$ \\
\hline Age (years) & $66.60 \pm 5.77^{b}$ & $64.60 \pm 4.28$ \\
\hline Gender (M/F) & $2 / 3$ & $1 / 4$ \\
\hline Height $(\mathrm{cm})$ & $160.20 \pm 6.91$ & $162.40 \pm 6.69$ \\
\hline Weight (kg) & $63.00 \pm 2.92$ & $65.60 \pm 2.79$ \\
\hline $\begin{array}{l}\text { Operation } \\
\text { (Rt/Lt) }\end{array}$ & $1 / 4$ & $3 / 2$ \\
\hline VAS $^{a}$ (score) & $3.00 \pm 0.71$ & $3.00 \pm 0.71$ \\
\hline
\end{tabular}

${ }^{\mathrm{a}}$ Visual analogue scale, ${ }^{\mathrm{b}}$ Mean \pm standard deviation

\section{B. Procedure}

The age, sex, height, weight, and pain of the study subjects were investigated based on medical records to ensure homogeneity between groups. In addition, it was confirmed that there was no statistical difference between groups in spatiotemporal gait parameters before intervention. There were 6 people in the PNF group who performed the PNF lower extremity pattern, and 6 people in the group who performed resistance training using equipment (control group). In both groups, a continuous passive exercise device (Artromot K-3 CPM, Ormed, Freiburg, Germany) was performed for 30 minutes prior to training. After that, the PNF group performed the PNF lower extremity pattern movement for 15 minutes, and the control group performed resistance exercise training for 15 minutes. It was conducted 5 times a week for a total of 2 weeks, and the amount of change was analyzed by measuring spatiotemporal gait parameters before and after training.

In the PNF group, the torso, pelvis, and legs were aligned in a lateral position with the operating side facing up on the treatment bed. In order to effectively strengthen the hip abductor and hip extensors, an extension-abduction-internal rotation pattern of the operating lower extremity was applied, and rhythmic initiation and combination of isotonic technique to strengthen muscle. Intervention was conducted by a researcher who completed level $3 \mathrm{a}$ of education conducted by the Society for PNF.

The control group performed lower extremity muscle strength exercises using resistance exercise equipment (M.E.T 200, CyberMedic, Iksan, Korea). The training was conducted by providing $70 \%$ resistance of $1 \mathrm{RM}$ while performing the knee joint extension motion while sitting with the trunk straightened. In order to minimize fatigue of the subjects, they were allowed to rest for 30 seconds after 10 times, and stopped when they complained of pain or fatigue.

\section{Gait assessment}

Biodex gait trainer 2 (Biodex gait trainer 2, Biodex Medical System Inc., USA) was used to assess spatiotemporal gait parameters of the subjects participating in the study. In this study, walking speed, step cycle, step length on the operated side and non-operated side, and time on each foot on the operated side were statistically processed. Walking exercises were performed for 3 minutes before the measurement, so that the subjects became familiar with the Biodex gait trainer 2, and the measurement was performed for 5 minutes after entering general information of the subject. In order to minimize errors during measurement, one researcher who has sufficiently practiced the operation of the measurement equipment performed the measurement. After the subject climbed on the treadmill, the investigator started at a speed of $0.3 \mathrm{~km} / \mathrm{h}$ and increased it by $0.1 \mathrm{~km} / \mathrm{h}$ to adjust to a comfortable speed. After that, measurement was started, and kinematic data recorded once were measured for statistical processing. The values measured by the Biodex gait trainer 2 are automatically compared with the standard values [11].

\section{Statistical analysis}

All statistical analyzes of this study were conducted using the Korean version of SPSS 22.0 (SPSS Inc., Chicago, IL, USA). Among the general characteristics of the PNF group and the control group, an independent t-test was performed for the normality for age, height, weight, and VAS, and a chi squared test was performed for the normality test for the gender and operation side. To examine the differences in general characteristics between the two groups, the MannWhitney $U$ test and the independent t-test was used. In addition, a paired t test was conducted to examine the changes before and after the spatiotemporal gait parameters of each group. In order to investigate the difference in the amount of change in spatiotemporal gait parameters between groups, the independent t-test were used. The significance level was 0.05 .

\section{RESULTS}

\section{A. Spatiotemporal gait parameters}

In the PNF group, all spatiotemporal gait parameters after intervention were improved compared to before intervention. In the control group, the results improved after intervention in speed and step length on the operated side $(p<0.05)$. In comparison between groups, the PNF group showed improved results in speed and step length on the non-operated side and time on each foot compared to the control group $(\mathrm{p}<0.05)($ Table 2$)$.

Table 2. Comparison of pre and post training outcome measures of walking ability within and between groups 


\begin{tabular}{|c|c|c|c|c|}
\hline & & $\begin{array}{c}\text { PNF } \\
\text { group }(n=5)\end{array}$ & $\begin{array}{c}\text { Control } \\
\text { group }(n=5)\end{array}$ & $\mathrm{p}$ \\
\hline Speed (m/s) & $\begin{array}{l}\text { Pre } \\
\text { Pos } \\
t \\
p\end{array}$ & $\begin{array}{c}0.33 \pm 0.19^{\mathrm{a}} \\
0.42 \pm 0.22 \\
0.02^{*}\end{array}$ & $\begin{array}{c}0.30 \pm 0.15 \\
0.32 \pm 0.13 \\
0.02^{*}\end{array}$ & $0.04^{\dagger}$ \\
\hline $\begin{array}{l}\text { Cycle } \\
(\text { steps/m) }\end{array}$ & $\begin{array}{l}\text { Pre } \\
\text { Pos } \\
t \\
p\end{array}$ & $\begin{array}{c}0.62 \pm 0.09 \\
0.68 \pm 0.09 \\
0.00^{*}\end{array}$ & $\begin{array}{c}0.58 \pm 0.12 \\
0.60 \pm 0.17 \\
0.49\end{array}$ & 0.44 \\
\hline \multicolumn{5}{|c|}{ Step length $(\mathrm{cm})$} \\
\hline Operated & $\begin{array}{l}\text { Pre } \\
\text { Pos } \\
\mathrm{t} \\
\mathrm{p}\end{array}$ & $\begin{array}{c}31.40 \pm 16.47 \\
35.40 \pm 15.65 \\
0.01^{*}\end{array}$ & $\begin{array}{c}29.80 \pm 17.81 \\
32.40 \pm 17.07 \\
0.00^{*}\end{array}$ & 0.13 \\
\hline $\begin{array}{l}\text { Non- } \\
\text { operated }\end{array}$ & $\begin{array}{l}\text { Pre } \\
\text { Pos } \\
\mathrm{t} \\
\mathrm{p}\end{array}$ & $\begin{array}{c}25.60 \pm 15.69 \\
31.60 \pm 15.14 \\
0.00^{*}\end{array}$ & $\begin{array}{c}26.00 \pm 15.25 \\
28.00 \pm 13.84 \\
0.06\end{array}$ & $0.00^{\dagger}$ \\
\hline \multicolumn{5}{|c|}{ Time on each foot $(\%)$} \\
\hline Operated & $\begin{array}{l}\text { Pre } \\
\text { Pos } \\
\mathrm{t} \\
\mathrm{p}\end{array}$ & $\begin{array}{c}43.80 \pm 2.86 \\
47.40 \pm 2.30 \\
0.00^{*}\end{array}$ & $\begin{array}{c}44.40 \pm 2.19 \\
46.00 \pm 2.00 \\
0.05\end{array}$ & $0.03^{\dagger}$ \\
\hline
\end{tabular}

${ }^{\mathrm{a}}$ Mean \pm standard deviation, significant difference between pre and post intervention within the group $\left({ }^{*} \mathrm{p}<0.05\right)$, significant difference between the change values among the groups $\left({ }^{\dagger} \mathrm{p}<0.05\right)$

\section{DISCUSSION}

This study was conducted to verify the effect of applying the PNF pattern to strengthen the hip extensor and hip extensors on the gait ability of patients with TKR, and to present a clinical method for rehabilitation of TKR patients.

The hip abductor muscle affects the regulation of pelvic movement during the stance phase during walking and is involved in hip joint stability [12]. Among the PNF pattern, the extension-abduction-internal rotation affects the stance phase during gait and is effective in improving spatiotemporal gait parameters [10]. In this study, when the PNF extensionabduction-internal rotation pattern was applied in the PNF group, all spatiotemporal gait parameters were improved after the intervention compared to the pre-intervention. The hip abductor muscle maintains and stabilizes trunk stability when walking. In particular, the transmission of force by the hip abductor muscle is an essential factor in controlling the movement of the pelvis relative to the femur during walking [13][14]. In other words, it is thought that the extensionabduction-internal rotation pattern conducted in this study effectively strengthens the hip abductor muscle, thereby improving the gait ability by playing the role of stabilizing the hip joint for the femur that is fixed during the stance phase.

In comparison between groups, the PNF group showed improved results in walking speed, step length on the nonoperated side, and time on each foot on the operated side compared to the control group. In a study by Schache et al. [15], it was reported that strengthening exercise for the hip abductor muscle was effective in improving gait ability compared to the strengthening exercise for the knee extensor muscle in total knee replacement patients. In this study, since muscle strength was strengthened for the hip abductor muscle compared with the control group in the PNF group only, it is thought that the result of improved gait ability was improved according to the improvement of physical function.

The PNF pattern applied in this study is an effective method to strengthen the muscles mobilized in the stance phase [16], and the lower extremity pattern extensionabduction-internal rotation also showed improved results of spatiotemporal gait parameters in the PNF group. Since the subjects of this study were subjects capable of performing the PNF lower limb pattern, it was possible to directly apply the pattern. However, in the case of the elderly with weak lower extremity muscle strength, there may be limitations in performing the correct posture [17][18]. To compensate for this, a method of indirectly activating the stance phase of the operated side by applying a flexion pattern to the opposite side to promote swing phase can be considered [10].

Since this study is based on subjects who visit a hospital and receive continuous management, there may be limitations in applying it to patients who are living daily. In addition, it is necessary to verify this as evaluation is only conducted after the intervention, and there is no evaluation on whether the future effect continues.

\section{CONCLUSION}

The purpose of this study was to verify the effect of PNF lower limb pattern application on gait ability in total knee replacement patients. The application of the PNF lower extremity pattern had an effect on the stance phase during walking by strengthening the hip abductor muscle, resulting in improved walking ability. Therefore, if you want to elicit an improved result of gait ability in patients with total knee replacement in the clinic, you should consider applying the PNF lower limb pattern.

\section{References}

[1] Christanell, F., Hoser, C., Huber, R., Fink, C., \& Luomajoki, H. The influence of electromyographic biofeedback therapy on knee extension following anterior cruciate ligament reconstruction: a randomized controlled trial, Sports Medicine, Arthroscopy, Rehabilitation, Therapy \& Technology, pp. 1-10, Volume 4, 2012.

[2] Iversen, M. D. Managing hip and knee osteoarthritis with exercise: what is the best prescription?, Therapeutic advances in musculoskeletal disease, pp. 279-290, Volume 2, 2010.

[3] Bade, M. J., Kohrt, W. M., \& Stevens-Lapsley, J. E. Outcomes before and after total knee arthroplasty compared to healthy adults, journal of orthopaedic \& sports physical therapy, pp. 559-567, Volume 40, 2010.

[4] Levinger, P., Menz, H. B., Morrow, A. D., Wee, E., Feller, J. A., Bartlett, J. R., \& Bergman, N. Lower limb proprioception deficits persist following knee replacement surgery despite improvements in knee extension strength, Knee Surgery, Sports Traumatology, Arthroscopy, pp. 1097-1103, Volume 20, 2012. 
[5] Bączkowicz, D., Skiba, G., Czerner, M., \& Majorczyk, E. Gait and functional status analysis before and after total knee arthroplasty, The Knee, pp. 888-896, Volume $25,2018$.

[6] Harikesavan, K., Chakravarty, R. D., Maiya, A. G., Hegde, S. P., \& Shivanna, S. Y. Hip abductor strengthening improves physical function following total knee replacement: one-year follow-up of a randomized pilot study, The open rheumatology journal, pp. 30, Volume 11, 2017.

[7] Piva, S. R., Teixeira, P. E., Almeida, G. J., Gil, A. B., DiGioia III, A. M., Levison, T. J., \& Fitzgerald, G. K. Contribution of hip abductor strength to physical function in patients with total knee arthroplasty, Physical therapy, pp. 225-233, Volume 91, 2011.

[8] Petterson, S. C., Mizner, R. L., Stevens, J. E., Raisis, L. E. O., Bodenstab, A., Newcomb, W., \& Snyder- Mackler, L. Improved function from progressive strengthening interventions after total knee arthroplasty: a randomized clinical trial with an imbedded prospective cohort, Arthritis Care \& Research, pp. 174-183, Volume 61, 2009

[9] Kofotolis, N. D., \& Kellis, E. Cross-training effects of a proprioceptive neuromuscular facilitation exercise programme on knee musculature, Physical Therapy in Sport, pp. 109-116, Volume 8, 2007.

[10] Alder SS, Beckers D, Buck M. PNF in practice: an illustrated guide, 4th ed, Berlin, Springer-Verlag, 2014

[11] Gharib, N. M., El-Maksoud, G. M. A., \& Rezk-Allah, S. S. Efficacy of gait trainer as an adjunct to traditional physical therapy on walking performance in hemiparetic cerebral palsied children: a randomized controlled trial, Clinical Rehabilitation, pp. 924-934, Volume 25, 2011.

[12] Friel, K., McLean, N., Myers, C., \& Caceres, M. Ipsilateral hip abductor weakness after inversion ankle sprain, Journal of athletic training, pp. 74, Volume 41, 2006.

[13] Earl, J. E. Gluteus medius activity during 3 variations of isometric single-leg stance, Journal of Sport Rehabilitation, pp. 1-11, Volume 14, 2005.

[14] Neumann DA. Kinesiology of the musculoskeletal system: foundations for physical rehabilitation, St. Louis, Mosby, 2002

[15] Schache, M. B., McClelland, J. A., \& Webster, K. E. . Does the addition of hip strengthening exercises improve outcomes following total knee arthroplasty? A study protocol for a randomized trial, BMC musculoskeletal disorders, pp. 1-12, Volume 17, 2012.

[16] Lee, Y. M., Ham, M. S., \& Kim, T. S. Effect of nonparalyzed side and paralyzed side of elastic band combined with proprioceptive neuromuscular facilitation lower extremity patterns on balance in chronic stroke patients, PNF and Movement, pp. 181-188, Volume 13, 2015.

[17] Luay Abu-Qatouseh, Eyad Mallah, Mona Bustami, Emad Alkhateeb, Increased Resistance of Fluoroquinolones among H. pylori Isolates from Patients with Gastroduodenal Diseases in Jordan, WSEAS Transactions on Biology and Biomedicine, pp. 76-81, Volume 17, 2020.
[18] Iason S. Mavromatakis, Sotirios G. Liliopoulos, George S. Stavrakakis, Optimized Intermittent Pharmaceutical Treatment of Cancer using Non-Linear Optimal Control Techniques, WSEAS Transactions on Biology and Biomedicine, pp. 67-75, Volume 17, 2020.

Contribution of individual authors to the creation of a scientific article (ghostwriting policy)

Author Contributions: Please, indicate the role and the contribution of each author:

Jin, Park: He was in charge of the overall progress of the research and writing the paper.

\section{Sources of funding for research presented in a scientific article or scientific article itself}

Report potential sources of funding if there is any

Creative Commons Attribution License 4.0 (Attribution 4.0 International, CC BY 4.0)

This article is published under the terms of the Cre ative Commons Attribution License 4.0

https://creativecommons.org/licenses/by/4.0/deed.en_US 